\title{
Inquiry Guided Learning Projects for the Development of Critical Thinking in the College Classroom: A pilot study
}

\author{
Danielle C. Bentley, University of Toronto, APLUS Institute of Dental Hygiene
}

\begin{abstract}
This paper describes the inaugural success of implementing Inquiry Guided Learning Projects within a college-level human anatomy and physiology course. In this context, scientific inquiry was used as a means of developing skills required for critical thinking among students. The projects were loosely designed using the Information Search Process (Kuhlthau, 1991) as a framework with emphasis placed on three of the six stages: question selection, scientific research, and presentation of results. The projects were quantitatively assessed using selfreported confidence ratings using a 10-point Likert scale. The projects were also qualitatively assessed using student feedback focusing on student suggestions for project improvement. Moving forward, the Inquiry Guided Learning Projects will be integrated as a formal course component, with the next stage of implementation to include a thorough assessment of student learning outcomes.
\end{abstract}

\section{Introduction}

The ability to independently analyze, synthesize, and evaluate information, otherwise called critical thinking, is viewed as an essential component of college training (American Association for the Advancement of Science (AAAS), 1990, 1993, 2010). Despite the importance of critical thinking, all too often in post-secondary science courses curricula are designed so that established scientific facts/understandings are merely presented to students. The promotion of this surface level learning can be intensified by the increased reliance on poorly designed multiple choice tests which can promote rote memorization among students (Stanger-Hall, 2012). In these content-heavy course environments students may develop passive learning strategies where they rely on the course instructor to 'give them' knowledge in a unidirectional conversation-style dialogue.

In order to evade this passive reliance on unidirectional learning, students at APLUS Institute of Dental Hygiene participate in novel and innovative educational strategies within their biomedical science courses, such as Movement Guided Learning (Bentley, 2013). Most recently, Inquiry Guided Learning Projects (IGLPs) were introduced to both first and second term students as an inaugural pilot study.

This pilot study had two research goals. The primary research goal was to evaluate improvement in students' self-perceived abilities to complete tasks pertaining to critical thinking. The secondary research goal was to determine project components that could be adjusted to more effectively meet the needs of students.

\section{Inquiry Guided Learning Project Design and Implementation}


Active learning strategies, specifically the strategy of scientific inquiry, have been shown to produce superior learning outcomes in various postsecondary science education environments (Baum, 2013; Luckie et al., 2012; Prince \& Felder, 2007). Building from this previous postsecondary success, Inquiry Guided Learning Projects (IGLPs) were used as a strategy to develop skills pertaining to critical thinking. As such, the IGLPs were designed with the intent of loosely guiding students through the six stages of the Information Search Process: initiation, selection, exploration, formulation, collection, and presentation (Kuhlthau, 1991). Three of the six stages (selection, formulation, and presentation) are imperative directly to the process of guided inquiry as it pertains to the IGLPs. Throughout the project these stages were referred to as Research Question Selection, Research Answer Formulation, and Research Answer Presentation accordingly.

The IGLPs were introduced to students on the first day of the course semester. At this point, students were randomly divided into small groups of 3-4 and instructed to brainstorm a research question that they would be genuinely interested in developing an answer to. The only limitations to their group questions were that the question topic had to come from the overarching theme of 'science', and that the question had to be specific enough that a single answer could be realistically formed. Some examples of student questions include: How do bees navigate our world? Why is the centre of the earth so hot? Does the use of colour affect our ability to memorize? How is the influenza vaccine made each year?

Throughout the semester student groups participated in three pre-scheduled check-ins with the course instructor. At each of the check-ins students were required to have completed previously communicated expectations. The purpose of outlined expectations was two-fold: to ensure project progress was occurring throughout the semester, and to provide guidance so students were moving through the stages of the Information Search Process as anticipated. Table 1 below outlines the check-in expectations.

Table 1 Description of inquiry project check-ins

\begin{tabular}{|c|c|c|}
\hline & Time Point & Group Expectations \\
\hline $\begin{array}{l}\text { Check- } \\
\text { In One }\end{array}$ & $\begin{array}{l}1 / 4 \text { through } \\
\text { the semester }\end{array}$ & $\begin{array}{l}\text { - } \text { Research question chosen based on initial assessment of current } \\
\text { literature } \\
\text { - } \quad \text { Project tasks divided among group members }\end{array}$ \\
\hline $\begin{array}{l}\text { Check- } \\
\text { In Two }\end{array}$ & $\begin{array}{l}1 / 2 \text { through } \\
\text { the semester }\end{array}$ & $\begin{array}{ll}\text { - } & \text { Completed thorough research of scientific literature } \\
\text { - } & \text { Formulated a research answer } \\
\text { - } & \text { Provided evidence of 'misdirected' research paths and necessary } \\
& \text { research adjustments that were utilized }\end{array}$ \\
\hline $\begin{array}{l}\text { Check- } \\
\text { In Three }\end{array}$ & $\begin{array}{l}3 / 4 \text { through } \\
\text { the semester }\end{array}$ & 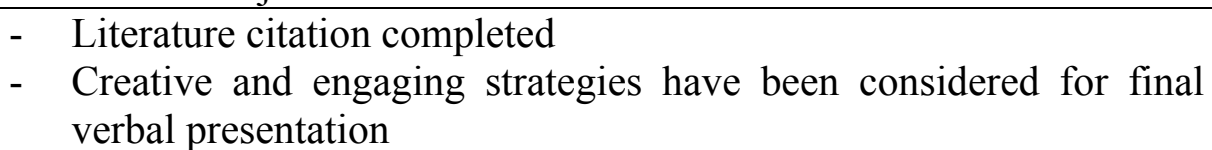 \\
\hline
\end{tabular}

To conclude the semester, each group prepared a 10 minute in-class oral presentation. Final project marks were determined using a combination of evaluations. In descending order of grade weight these evaluations included instructor assigned marks based on both individual performance and overall group performance during final presentation, student self-assigned marks based on their completion of project tasks throughout the semester, and peer-assigned marks based on their completion of project tasks throughout the semester. 
Formal research assessment of the IGLPs occurred in two ways. Quantitatively, students' self-reported their perceived ability to perform the aforementioned tasks of Research Question Selection, Research Answer Formulation, and Research Answer Presentation at two time points; at the beginning of the semester (pre-IGLP) and at the end the semester (post-IGLP). To complete this self-assessment a 10-point Likert scale was used with 10-(the strongest) through to 1-(the weakest). Pre-IGLP to post-IGLP were compared using a paired Student's t-test with statistical significance set at $p=0.05$. All statistics are presented as mean \pm standard deviation. Qualitatively, students provided anonymous open-ended feedback in regards to the project structure, the allocation of group members, time commitment, question generation, selfevaluation of student learning, and progression of skill development. With this being the inaugural pilot implementation, the information collected from student feedback was imperative to the refinement of the project.

\section{Results of Inaugural IGLP Implementation}

A total of 29 first $(n=11)$ and second term $(n=18)$ students were divided into 9 small groups. Each group successfully completed the IGLP by providing a scientifically justified answer to a self-generated research question. Overall, students' performances throughout the IGLPs were extremely high resulting in a class average of $82.3 \pm 4.8 \%$.

Following the completion of the IGLP students indicated they were more confident in their ability to Select a Research Question $(6.9 \pm 1.9$ to $8.5 \pm 1.3, \mathrm{t}(28)=-6.35 \mathrm{p}<0.01)$, they were more confident in their ability to Formulate an Answer to a Research Question (6.0 1.8 to $8.1 \pm 1.3, \mathrm{t}(28)=-6.76, \mathrm{p}<0.05)$, and they were more confident in their ability to Present the Answer to a Research Question $(6.2 \pm 1.9$ to $8.0 \pm 1.6, \mathrm{t}(28)=-6.20, \mathrm{p}<0.01)$.

Students enjoyed the Inquiry Guided Learning Projects (7.9 \pm 2.3$)$ while at the same time finding the project to be academically challenging (7.8 \pm 1.8$)$. Despite indicating the academic challenge of the project, $100 \%$ of students recommended that the IGLP be continued at APLUS Institute.

Qualitative feedback revealed that students would prefer more rigorous direction from the course instructor. For many of them this was the first time they had to find and read peerreviewed journal articles in order to extract important information. Students indicated that more detailed information would be useful on the topics of; how to find journal articles, how to read them, how to understand what the statistics meant, how to correctly cite journal articles, and how to synthesize information into one summarized answer.

\section{Moving Forward}

With the success of the pilot implementation of the Inquiry Guided Learning Projects at APLUS Institute, the decision has been made to formally incorporate this teaching and learning strategy in the Gross Anatomy and General Physiology first semester course. As part of this full incorporation a thorough research assessment of academic effectiveness and student enjoyment will occur, approved by the University of Toronto Research ethics board and led by the course instructor. This thorough assessment is currently underway.

Changes that have been made to the IGLP are based on both the quantitative results of students' own abilities and the qualitative feedback provided by students. One of the more impactful changes is the addition of four Information Sessions that will be scattered throughout the semester. The information sessions have been designed to provide condensed information on topics pertaining to: Question Selection and Group Communication Strategies, How to Perform 
an Academic Article Search, APA Referencing, and Verbal Presentation Skills. It is anticipated that these Information Sessions will be most useful for students new to the process of critical thinking and scientific research.

Assessment of the new IGLP structure will again occur using student self-perceived ranking of research confidence and research ability. In addition, student learning preferences (as defined by Fleming's VARK Questionnaire (Fleming \& Mills, 1992)) and learning styles (as defined by Kolb's Learning Styles Inventory (Kolb, 1984)) will be considered as covariates in overall performance to determine if a project of this nature is more likely to be successful for certain student learners.It is predicted that the IGLP will be positively received among students, yet will challenge them through the process of determining a research direction, scouring current academic literature to synthesize an answer, and presenting the answer to their research question in an engaging and stimulating manner.

\section{Conclusion}

The full preparation of future health care professionals involves more than just the dissemination of rote facts or the mastery of health care techniques. It is imperative that we also equip these future professionals with the skills required to properly critique information in the scientific community around them. The ability to independently analyze, synthesize, and evaluate information will lead to future success in health care. As a means of developing critical thinkers, learning strategies based on inquiry, such as the IGLPs, can prepare students to be active and engaged professionals possessing the skills for academic discovery following formal education.

\section{Author's Biography}

Danielle Bentley is currently a doctoral student at the University of Toronto studying cardiovascular physiology. Since January of 2011 she has been an instructor for numerous courses in the field of human anatomy and pathophysiology at APLUS Institute of Dental Hygiene. As an educator, Danielle is interested in the development and analysis of both experiential and interactive learning strategies. 


\section{References}

(AAAS), A. A. f. t. A. o. S. (1990). Science for All Americans. New York: Oxford University Press.

AAAS. (1993). Benchmarks for Science Literacy. New York: Oxford University Press.

AAAS. (2010). Vision and Change: A Call to Action. Washington, DC: AAAS.

Baum, E. J. (2013). Augmenting Guided-Learning With a Blended Classroom Approach. Journal of College Science Teaching, 42(6), 27-33.

Bentley, D. (2013). Movement Guided Learning(C as a Means of Musculoskeletal Anatomy Instruction. Journal of the Federation of American Societies of Experimental Biology, 27, 960.965.

Fleming, N., \& Mills, C. (1992). Not Another Inventory, Rather a Catalyst for Reflection. To Improve the Academy, 11, 137-155.

Kolb, D. (1984). Experiential Learning: experience as the source of learning and development. Anglewood Cliffs: NJ: Prentice Hall.

Kuhlthau, C. (1991). Inside the search process: Information seeking from the user's perspective. Journal of the American Society for Information Science, 42(5), 361-371.

Luckie, D. B., Aubry, J. R., Marengo, B. J., Rivkin, A. M., Foos, L. A., \& Maleszewski, J. J. (2012). Less teaching, more learning: 10-yr study supports increasing student learning through less coverage and more inquiry. Adv Physiol Educ, 36(4), 325-335. doi: 10.1152/advan.00017.2012

Prince, M., \& Felder, R. (2007). The Many Faces of Inductive Teaching and Learning. Journal of College Science Teaching, 36(5), 14-20.

Stanger-Hall, K. F. (2012). Multiple-choice exams: an obstacle for higher-level thinking in introductory science classes. CBE Life Sci Educ, 11(3), 294-306. doi: 10.1187/cbe.11-110100 